\title{
A LITERARY CRITICAL COMPARISON OF THE MASORETIC TEXT AND SEPTUAGINT OF DANIEL $2-7^{1}$
}

\section{Tim Meadowcroft}

One of the many challenges of the book of Daniel is that the Septuagint version of the book diverges from the Masoretic Text (MT) in significant ways, especially, but not only, in chapters 3-6. At the same time, another version known as Theodotion has become the well known and better attested Greek version of Daniel. Neither of these phenomena on their own are unique in the Greek Bible. The apparent freedom of the translators of Job or Proverbs is well known, and the presence of a differing Greek tradition is also a feature of the history of the book of Esther. What is unique about the Greek translation of Daniel is that somewhere in the history of the Greek Bible the Septuagint of Daniel was replaced by Theodotion, which is much closer to the Masoretic Text, as the authoritative Greek version.

My purpose in this dissertation is to explore the curious situation outlined above by applying the tools of narrative criticism to a comparison of the Masoretic Text and the Septuagint of Daniel 2-7. The choice of those particular chapters is based partly on the fact that they are in Aramaic in MT, and partly on form critical work which identifies chapters 2-7 as a coherent unit within the book as a whole. The choice of the particular tools of narrative criticism aids in a consideration of whether or not the two versions differ significantly in the way in which they tell their stories. Such an approach seeks to treat the Septuagint as a literary creation with its own integrity,

\footnotetext{
1T.J. Meadowcroft, A Literary Critical Comparison of the Masoretic Text and Septuagint of Daniel 2:7 (Unpublished Ph.D. thesis, New College, University of Edinburgh, 1993); supervisors: Dr A.P. Hayman and A.G. Auld.
} 
and as a collection of writings that at some stage has possibly been accorded authoritative status, where more often than not it has been treated simply as a mine of historical critical information to be quarried in assessing the Masoretic Text.

The thesis undertakes the comparison chapter by chapter, but at each stage considers the way the particular story in question relates to the wider unit of which it is a part. The order of treatment is informed by Lenglet's analysis of the literary structure of Daniel, namely that the Masoretic Text is in the form of a chiasm centred around chapters 4-5. I treat those central stories first before moving to chapters 3 and 6 , and finally the outer pairing of chapters 2 and 7. I draw on the work of others to defend the assumption that most of the time the Septuagint is a reasonably accurate translation of its Semitic Vorlage, which means that where there are substantial differences between the versions the Septuagint has probably been working from a text that differs from the Masoretic Text. However I take issue with the work of Jeansonne by suggesting that there are aspects of Septuagintal translation that betray a particular mind set on the part of the translator. A survey chapter on differences between the versions in chapters $1,8-12$ is included as a check on findings from chapters 2-7. Theodotion's translation is treated briefly in one appendix while another provides an English translation of the Septuagint of Daniel 2-7.

Three types of conclusion arise out of all this: literary, thematic and historical. The literary and thematic aspects are to be expected from such a thesis. The historical conclusions are not so expected, but it proved both impossible and wrong to divorce the literary study entirely from the historical. As a result several historical conclusions about the development of the versions and their relationship to one another are tentatively drawn from the data assembled.

\section{Literary Conclusions}

The key difference between the narratives of the Septuagint and the Masoretic Text is to be found in the role the narrator plays. The MT narrator is more covert where his Septuagint counterpart tends to be more overt. This distinction manifests 
itself in several ways, such as in the portrayal of human motives and emotions. The Septuagint narrator consistently specifies the motives behind characters' actions where the MT reader is left to deduce them for himself. In much the same way the Septuagint narrator betrays a position outwith the story where the Masoretic Text generally observes the temporal and spatial limitations of the participants. The covert stance of the Aramaic narrator is characteristic of biblical narrative generally. Because of the more covert role of the MT narrator, the Aramaic narrative is highly dependent on a range of literary devices for the portrayal of point of view. Variations in dialogue repetition, the risky use of irony and even parody, and the adjustment of 'camera angle' in the story are all employed to this end. In contrast the Septuagint often shares a relatively more omniscient outlook with the reader, with the result that the subtlety and potential ambiguity evident in MT is less often present.

There are striking differences in the way the chapters are linked to one another. Most obvious in the Masoretic Text is the Nebuchadnezzar material common to chapters 4 and 5, and which binds the two chapters together in literary and thematic terms. There is no such common material in the Septuagint of those two chapters, but the Greek version of chapter 4 seems to draw heavily on the Greek additions that precede it in chapter 3. It could be that the Septuagint points back to a different structure, perhaps the one reflected in Chester Beatty Papyrus 967 , where chapters 7 and 8 are interposed between chapters 4 and 5.

\section{Thematic Conclusions}

Related to differences in narrative form and structure are differences in the way the two versions treat the symbolic. Notwithstanding the lack of an agreed vocabulary with which to discuss these matters, the Masoretic Text charts a subtle interplay between the human and the divine which defies neat categorisations. The two planes interact particularly in chapters 2 and 7, but are not sharply distinguished. There is no clear distinction between vision and interpretation, divine messenger and earthly manifestation, between the heavenly battle and 
temporal events. The overt narration of the Septuagint seeks to clarify the lines and to understand events much more in allegorical terms with neat one-to-one correspondences between the divine and the human.

Wisdom is also viewed differently by the two versions. The wisdom of Daniel in MT is portrayed in more mantic terms, where the protagonist is 'chief' of the magicians. The Greek shies away from too ready an identification of Daniel with his pagan counterparts, and prefers to see him more as a wise leader in the Jewish community. In a similar vein the view taken of Nebuchadnezzar by the Septuagint is more reminiscent of the attitude toward the evil regime of chapters 712 and less of the Babylonian/Persian setting conveyed in the Aramaic. As a result, MT is more universalist in emphasis and the Septuagint more concerned with Israelite nation and cult.

\section{Historical Conclusions}

The Septuagint seems to take us both closer to an Ursprung and further away from the putative Persian provenance of the Aramaic. Historical critical approaches have not so far been notably successful in holding the two tendencies evident in the Septuagint together. The literary data in this thesis suggests that the earliest collation in the tradition represented by MT was chapters 4-6, and possibly also chapter 3. Chapters 2 and 7 are later, although the core of chapter 2 is a somewhat earlier composition than chapter 7. A feeling for Nebuchadnezzar and a positive view of Daniel's courtly role influenced this tradition from early in the process of its formation. At the same time there must have been a differing Aramaic tradition, also in the Persian exile, which grew out of the same pool of stories and which is reflected in the Septuagint. This contained a more hostile view of Nebuchadnezzar and a less mantic conception of the wisdom of Daniel, and it is this material that seems to point us behind the Masoretic Text. As a direct result of the Antiochene crisis, the stories were finally collected in Palestine in the first half of the second century BCE, and combined with the visions. The stories and visions were soon translated into Greek, using the Aramaic circle that represented the more Palestinian outlook. It is at this stage that the translator's 
unfamiliarity with the earlier period becomes evident. The Masoretic Text compilation, however, was more universalist and not so sympathetic to the more nationalist Hasmonean or Maccabean approach. Two major arguments against this hypothesis are suggested. One is that it is surprising that a Palestinian tradition should have been translated into Greek at all. A second arises out of the MT, where the evidence of P967 indicates that the final redaction took place well after the Persian period. Why then is the less hostile view of the Gentile kings retained even after the visions are attached to the stories? It could be a reflection of the literary sophistication of the Masoretic Text, but that is not a historical answer.

\section{Prospects}

This thesis only examines one aspect of a much larger problem. Most obviously it only deals with part of Daniel. It also needs to be supplemented by further study of the linguistic evidence in the Aramaic of Daniel, by more thorough reflection on narrative and realism, and by an exploration from a theological point of view of the usefulness of narrative criticism as a tool in biblical studies. 